RAS, the maintenance of international contacts, a decisive turn to interdisciplinary methods of analysis, and protection of humanistic stand inherent to Russian science throughout its history are the main challenges to the RAS.

Keywords: academic community, humanism, individual, knowledge production, science, social institution, structuralfunctional organization, Russian Academy of Sciences

ПОСУХОВА Оксана Юрьевна - кандидат социологических наук, доцент; доцент Южного федерального университета (344006, Россия, г. Ростов-на-Дону, ул. Б. Садовая, 105/42, оф. 506-а; belloks@yandex.ru)

\title{
РОЛЬ ПРОФЕССИОНАЛЬНЫХ ДИНАСТИЙ В АКАДЕМИЧЕСКОЙ СРЕДЕ РОССИЙСКОГО ОБЩЕСТВА
}

\begin{abstract}
Аннотация. Академические династии являются одним из институтов воспроизводства и развития научной деятельности, их можно рассматривать как носители интеллектуального и символического капитала. Вместе с тем роль профессиональных династий в академической среде может оцениваться двояко. Конструктивность академических династий проявляется в социализации молодого поколения, создании профессионального фона не только для членов династии, но и для других и становится при этом ядром успешно действующих научных коллективов. Династии также могут рассматриваться как носители стандартов профессионализма, обеспечивающие устойчивое развитие научной среды. Но династия может представлять собой не только механизм преемственности научной деятельности, но и монополию, которая способствует возникновению фильтров, закрытости научного сообщества, что говорит о ее деструктивном потенциале.
\end{abstract}

Ключевые слова: академическая династия, профессионализм, монополия, ресурсы, символический капитал

П рофессиональные династии в академической среде неоднозначно воспринимаются в российском обществе. С одной стороны, сохраняется высокий авторитет академического сообщества как носителя культуры и знаний, с другой - еще в предшествующий советский период сложился стереотип о неприятии династийности в обществе, где официально пропагандировался образ рабочих династий [Ткач 2007].

В советском обществе ученые занимали устойчивое место в должностной иерархии: им гарантировались значительные бонусы в виде материальных и символических льгот ${ }^{1}$. Факторами, определяющими академическую карьеру, были талант ученого и одновременно его лояльность по отношению к партии и государству. Временами академическая среда демонстрировала принципиальность в отборе кандидатов в академическое сообщество (отклонение кандидатур партийных деятелей, например, С.П. Трапезникова) [Кривоносов 2004: 169]. Принципиальная позиция академического сообщества, которая вызывала неудовольствие и раздражение партийных структур, заключалась в том, чтобы не руководствоваться в подборе академических кадров никакими критериями, кроме профессионализма и преданности науке. Этос академического сообщества был ориентирован на корпоративизм, на введение в механизм карьерных регуляторов авторитета, заслуг, солидарности. Вместе с тем академическое карьерное пространство как совокупность позиций, установок и отношений в рамках построения карьеры не исключало и неформальный механизм [Млечин 2018].

\footnotetext{
${ }^{1}$ Торгашев В.А. Вспоминая СССР. Доступ: https://nstarikov.ru/blog/23233 (проверено 08.07.2018).
} 
В конце 1970-х - начале 1980-х гг. в академическом сообществе проявляется династийность (академическая семья Патонов, семья Арбатовых). Несмотря на политику неодобрения семейственности со стороны партийных структур [Млечин 2018], академическое сообщество в контексте элитизации относилось в большей степени сдержанно к такой форме профессионального рекрутирования. Причина заключалась в том, что здесь проявлялись двойные стандарты: риторика общества равенства противоречила реальному социальному неравенству. Хотя социальные стратификационные разрывы не носили такой угрожающий характер, как сейчас, советское общество было отнюдь не свободно от неравенства в системе образования, трансмиссии статусов, свойственного и другим обществам [Россия... 2001: 148]. Происходило формирование карьерных практик, определяемых схемой: элитная школа - элитарный вуз - академическая структура. Примечательно, что кузницей таких кадров был МГИМО. В естественных науках высоко котировались МИФИ и МФТИ. Однако существовали и различия в построении карьер. Так, выпускники МГИМО закреплялись на номенклатурных должностях не только в науке, но и в сфере дипломатии, журналистики, партийных органов. А выпускники-физики ориентировались преимущественно на научную сферу. Можно говорить о том, что династический фактор принимал различные формы: в гуманитарном секторе он был связан с актуализацией семейного капитала и связей, в естественнонаучном - использовал поддержку со стороны альма-матер.

В 1990-х гг. стабильная ситуация в научной сфере, сложившаяся в советский период, резко изменилась: фиксируется падение ее престижа и, как следствие, отток научных кадров [Бляхер 2015]. Причина падения престижа российской науки, ее вклада на фундаментальном и прикладном уровне связана не только с отсутствием финансирования, но и со старением кадрового состава и резким падением стандартов профессионализма. Как подчеркивали российские социологи, привлекательность российских вузов в 90 -е гг. XX в. резко снизилась в результате потери преимуществ подготовки по фундаментальным дисциплинам [Шереги, Дмитриев, Арефьев 2002: 34]. Такой неблагоприятный поворот в развитии российского высшего образования, согласно выводам авторов, был связан с отходом от академической модели образования и потерей координации между вузами и академическим сообществом. Академическое сообщество, как и система высшего образования, стали функционировать на основе принципа замкнутости, сохранения позиций. В условиях, когда и авторитет науки, и профессия научного работника испытывали спад, династическая карьера становится адаптивной и сберегающей стратегией с ориентацией на стабильность, которая резко сузилась в других сферах профессиональной деятельности. При этом все же важным фактором остается мотивация к академической карьере, ее связь с престижными позициями в обществе. К тому же, хотя и в усеченной форме, сохранялись определенные льготы для высшего академического состава. В этих условиях семейная поддержка становится стартовой площадкой для профессиональной карьеры. Поэтому начиная с середины нулевых годов происходит повышение престижа российской науки. В 2013 г. россияне считали, что работать в науке в целом престижно, и одобрили бы выбор данной профессии для своих детей ${ }^{1}$; в 2016 г. выбор науки как профессии также вызывает одобрение 2 .

В академическом сообществе, хотя и сохранялись стандарты профессио-

\footnotetext{
1 Престиж науки в России. Опрос ВЦИОМ. Доступ: https://wciom.ru/index.php?id=236\&uid=1186

2 Индикаторы науки 2018: статистический сборник. М.: НИУ ВШЭ. 2018. 320 с. Доступ: https:// www.hse.ru/data/2018/02/12/1162058327/Science_and_Technology_Indicators_2018.pdf (проверено 08.07.2018).
} 
нализма, произошла их трансформация. Это нашло выражение в том, что на первое место вышел не когнитивный интерес, а прагматический, связанный с финансированием научно-исследовательских проектов. В академическом сообществе стала появляться конкуренция за финансовые и кадровые ресурсы [Душина, Ащеулова 2013: 162], что повышает привлекательность династического фактора, связанного с влиянием сплоченности в рамках возросшей конкуренции, способностью проталкивать собственные и групповые интересы, отстаивать их перед руководством.

В условиях ослабления государственных регуляторов кадровой политики в академическом мире возрос риск попадания «случайных людей», и династический фактор стал рассматриваться как барьер на пути соискателей академического статуса (академиков от бизнеса и политики). Доминировало мнение, что лучше средний выходец из научной среды, чем квазипрофессионал (хотя были и исключения в виде династии Жуковых) ${ }^{1}$. Кроме того, утвердилась позиция, что недостаток профессиональных знаний может быть преодолен в процессе «доучивания». Важно, что профессиональный актор придерживается негласных норм и правил академической среды, которые позволяют ему регулировать собственные профессиональные и карьерные амбиции, в то время как «случайный человек», исходя из прагматических интересов, может быть настроен на подчинение коллектива собственным интересам, привести свою команду, которая не обладает базовым образованием, но владеет навыками делового менеджмента.

Династический фактор в определенной степени способствовал сохранению ядра академического сообщества, воспроизводил матрицу стабильности. Однако в нынешних условиях, наряду с недостаточным финансированием, коммерциализацией научно-исследовательских проектов, очевидными становятся негативные последствия династизации профессиональной карьеры - при доминировании династического семейного капитала могут снижаться требования к профессионализму, возникает «синдром снисходительности» в оценке деятельности «своих» в силу доминирования двойных стандартов. Может формироваться и благоприятная почва для появления имитационных аналогов профессиональной деятельности [Волков 2016: 55]. Таким образом, конструктивность академических династий, характеризующих преемственность в развитии отечественной науки, здесь отступает на второй план.

Между тем академические династии образуют золотой фонд науки. Династии в академической среде можно рассматривать как носители интеллектуального и символического капитала. Об этом писал Дж. Бернал, когда подчеркивал, что во многом появление науки обязано кругу единомышленников и родственников [Бернал 1956: 142]. Несмотря на то что наука - это сфера творчества и не примлет протекционизма, нельзя не учитывать преемственность научного знания. Академические династии не случайны, и об этом свидетельствует тот факт, что важное значение имеет аскриптивный статус: карьера ученого не может быть абстрагирована от социализации и от того, что можно назвать стартовыми условиями. Если отвлечься от идеализированного представления о научной деятельности и анализировать ее исходя из конкретных обстоятельств и конкретных людей, то профессиональная карьера ученого связана не только с местом человека в окружающем его социуме и его предназначением, но и с принципами, которыми человек руководствуется [Тощенко 2016а: 138]. Это важное замечание относится к тому, что принципы, которыми руководствуются ученые, являются результатом габитуса, опыта, который формируется в

1 Страсть к науке по наследству. Доступ: https://lenta.ru/articles/2014/09/08/zukov/ (проверено 08.07.2018). 
семейной среде. Династийность конструктивна тем, что на уровне индивидуального выбора актор конструирует собственную систему жизненных ориентиров. Также важно и то, что он действует исходя не из норм, навязываемых обществом, а пропуская внешние влияния через схему собственных оценок, не в последнюю очередь сформированных посредством академической среды.

Братья Николай и Сергей Вавиловы реализовывали свою карьеру на поприще отечественной науки, и их судьбы сильно различаются. Всемирно известный генетик и агробиолог Николай Вавилов был репрессирован, а его брат Сергей достиг вершин академической карьеры, возглавляя АН СССР с 1945 по 1951 гг. Как личности они сформировались в академической среде, которая характеризовалась свободой творчества и независимостью оценок и суждений. В таком контексте даже трагическая судьба брата не позволила С. Вавилову оставить научную деятельность. Более того, осознавая горечь утраты на посту президента Академии наук, он прилагал усилия, чтобы сфера физики была не затронута вмешательством государственных структур. Подобная «семейственность» свидетельствует об определенном кодексе ученого: в этом смысле академические династии полезны тем, что сохраняют традиции научной среды. Не отрицая того, что академическая среда имеет «режим открытого доступа», т.е. институционально ориентируется на «зарабатывание» привилегий, можно также говорить о том, что в рамках академической среды формируются общие убеждения и по отношению к роли науки в обществе, и смыслу научной деятельности, а академические династии отличаются способностью поддерживать научную элиту вне непосредственных рамок государства [Норт, Уоллис, Вайнгаст 2011: 107].

Ж.Т. Тощенко пишет, что микросреда как совокупность институтов и отношений, составляющих непосредственное окружение человека, оказывает непосредственное влияние на формирование и развитие личности [Тощенко 2016б: 112]. Академические династии включены в состав социальной микросреды и в этом контексте не только создают профессиональный фон для членов династии, но и могут стать ядром успешно действующих научных коллективов. Однако следует учитывать и тот факт, что может проявиться застойность, сословность. В условиях доминирования неформальных связей проявляется тенденция к монополизации данной сферы, ее освоения как семейного дела. Следует подчеркнуть, что академические династии играли и будут играть ведущую роль в формировании научного сообщества, но при этом необходимо принимать во внимание как внешние, фоновые обстоятельства, так и внутренние - воспроизводство и развитие научной деятельности.

Если в обществе поддерживается высокий уровень социальной мобильности и сфера научно-исследовательской деятельности не только финансируется в достаточном объеме, но и обладает символическим капиталом, академические династии будут ориентированы на рост авторитета науки. В условиях же перехода к символам сословной принадлежности [Дискин 2011: 21] выхолащивается профессионализм в академических династиях, и доминирующими становятся знаки-различия и связанное с ними распознавание «своих и чужих». Подобная процедура идентификации может иметь в качестве последствия ослабление роли академических династий, т.к. на смену таким маркерам династийности, как престиж, семейная традиция, социальный капитал, приходит упрощенная схема, связанная с селекцией по критерию неформального капитала. Устойчивость «символической сословной принадлежности» сужает возможности для самовыражения других участников карьерного пространства, т.к. доминирует идентификация по наличию неформального капитала в ущерб коммуникации и творчеству [Гуцапенко 2013: 117]. Академические династии в нынешнем состоянии научной сферы оттесняются на периферию, и в реаль- 
ности династийность становится суррогатом неформальных схем устройства на работу, реализации карьерных возможностей, получения грантового финансирования. В пользу такого положения говорит тот факт, что происходит вымывание старых академических династий, которые воспроизводили этос научного сообщества и создавали фон суверенности научной деятельности. Потеря единого контроля над профессией (общепризнанных стандартов, ориентиров и компетентности) не только ослабляет фильтры профессионализма, но и создает диспаритет интересов и возможностей в пользу носителей определенных «правил» [Николаев 2003: 13].

Таким образом, династийный фактор, который имел большое значение для формирования научных и интеллектуальных элит, размывается в процессе отхода от модели академизма - приоритета норм профессионализма и компетентности. Отмечая это обстоятельство, можно также говорить о том, что исчезает понятие креативных профессионалов - тех, кто рассматривает показатель профессиональных достижений как символический капитал [Флорида 2011: 95]. Отсюда создание информационного вакуума вокруг академических династий, сведение династийности к алгоритму неформального капитала. Вместе с тем, как писал немецкий исследователь У. Бек, профессиональное образование, знания, навыки избыточными не стали, хотя и утратили статусно-распределяющую функцию [Бек 2000: 225]. Это означает, что в научной сфере, несмотря на экспансию неформальных схем, проявляется потребность в воспроизводстве профессионализма, в т.ч. и в возрождении академических династий. Речь не идет о том, чтобы искусственно поддерживать академические династии, тем самым создавая видимость преемственности научного сообщества. Академические династии должны ориентироваться на коммуникативность, налаживание диалога с обществом, тем самым создавая позитивный образ науки в массовом сознании.

Учитывая фактор конкурентности, интенсивности информационных потоков, контактов в научной среде, династийный фактор можно рассматривать по-новому. Речь идет о том, что в науке, где традиция и инновация действуют в связке, династии могут аккумулировать опыт консолидации научного сообщества, поддерживать авторитет науки. Как отмечал П. Бурдье, поля инвестиций ученых определяются как по их значимости, так и по их природе и зависят от размеров наличного и потенциального капитала признания и от позиций достигнутой и потенциальной [Бурдье 2005: 27]. Это означает, что династия вносит инвестиции в развитие науки в двух ситуациях. Во-первых, когда научная деятельность может подвергаться остракизму, и авторитет династии и ее связи в политических элитах могут предотвратить радикальные действия. Вторая ситуация связана с тем, что инновации в научной деятельности проходят длительный период признания, и символический капитал династий способствует их легитимации, даже если в обществе существует определенный скепсис.

Академические династии ассоциируются с фундаментальной наукой, т.к. важным является их значение в налаживании интергенерационного диалога внутри научного сообщества. Династийность создает принадлежность и к традиции, и к научной школе, придает дух избранности и приверженности профессионализму в условиях, когда в научные сообщества внедряются коммерческие и потребительские настроения. Российское научное сообщество нуждается в династической традиции. Это обусловлено тем, что с утерей династий вымывается научный этос и, несмотря на возможность монополизации, династический фактор стимулирует развитие новых научных школ и направлений. Важно также отметить, что в российском обществе, где достаточно сильны неформальные карьерные механизмы, в научной среде, если говорить о перспективах 
карьерного роста, династическое наследование является более плодотворным, чем протекционизм и семейственность в других сферах общественной жизни.

Академические династии являются институтом воспроизводства и развития научной деятельности. Исходя из этого, можно говорить о том, что династия выполняет важную роль в социализации ученой среды, в формировании «дисциплинарного мышления». Учитывая актуальность легитимации научной карьеры в нынешних условиях, важно отметить роль династий и как носителей научного этоса, и как способа идентификации с научным сообществом.

Не менее важно подчеркнуть, что следует различать династический фактор как механизм преемственности научной деятельности и монополию, которая может способствовать возникновению сословных фильтров, закрытости научного сообщества. В этом смысле династический фактор конструктивен тем, что поддерживает культуру научной компетентности.

\section{Список литературы}

Бек У. 2000. Общество риска. М.: Прогресс-Традиция. 383 с.

Бернал Дж. 1956. Наука в истории общества. М.: Издательство иностранной литературы. 736 с.

Бляхер Л. 2015. Провинциальная наука в «лихие 90-е»: время упущенных возможностей. - Знак вопроса. № 2. С. 45-52. Доступ: http://gefter.ru/archive/14963 (проверено 08.07.2018).

Бурдье П. 2005. Поле науки. - Sociologos 2005. Социология под вопросом. Социальные науки в постструктуралистской перспективе. М.: Праксис; Институт экспериментальной социологии. 304 с.

Волков Ю.Г. 2016. Социальная имитация: опыт анализа символической социальной реальности. Ростов Н/Д: Изд-во ЮФУ. 112 с.

Гуцапенко Л.А. 2013. Социальные инновации и квазиинновации в человеческом измерении. - Новые идеи в социологии. М.: ЮНИТИ-ДАНА. 479 с.

Дискин И.А. 2011. Россия, которая возможна. М.: Юрист. 175 с.

Душина С.А., Ащеулова Н.А. 2013. Академическая карьера ученого: обзор семинара. - Социология науки и технологий. Т. 4. № 2. С. 158-163.

Кривоносов Ю.И. 2004. Академические выборы: два конфликта с властью с разницей в 38 лет. - ИИЕТ РАН. Годичная научная конференция. М.: Диполь-Т. 224 с. Доступ: http://www.ihst.ru/projects/sohist/papers/ihst/2004/krivonosov.htm (проверено 08.07.2018).

Млечин Л. 2018. Династии, кланы и семьи в России. От Ленина до Путина. М.: Центрполиграф. 320 с.

Николаев В.Г. 2003. Условия и перспективы социологии в современной России: к социологии российских социологий. - Социология и современная Россия. М.: ГУ-ВШЭ. С. 5-25.

Норт Д., Уоллис Дж., Вайнгаст Б. 2011. Насилие и социальные порядки. Концептуальные рамки для интерпретации письменной истории человечества. М.: Изд-во Института Гайдара. 480 с.

Россия: трансформирующееся общество (под ред. В.А. Ядова). 2001. М.: КанонПресс-Ц. 640 с.

Ткач О.А. 2007. Заводские династии в современных рыночных условиях. Человек и труд. № 12. С. 69-81. Доступ: http://chelt.ru/2007/12-07/tka4_12-7.html (проверено 08.07.2018).

Тощенко Ж.Т. 2016а. Смысл жизни: новое в теории и методологии социологического знания. - Проблемы теоретической социологии. Вып. 11. СПб: Изд-во СПбГУ. С. 134-147.

Тощенко Ж.Т. 2016б. Социология жизни. М.: ЮНИТИ-ДАНА. 399 с. 
Флорида Р. 2011. Креативный класс:люди, которые меняют мир. М.: КлассикаXXI. 430 c.

Шереги Ф.И., Дмитриев Н.М., Арефьев А.Л. 2002. Научно-педагогический потенциал и экспорт образовательных услуг российских вузов (социологический анализ). М.: Центр социального прогнозирования. 552 с.

\title{
THE ROLE OF PROFESSIONAL DYNASTIES IN THE RUSSIAN ACADEMIC ENVIRONMENT
}

\begin{abstract}
Academic dynasties are one of the institutions of reproduction and development of scientific activity; they can be regarded as carriers of intellectual and symbolic capital. However, one can consider the role of professional dynasties in the academic environment in two ways. The constructiveness of academic dynasties manifests itself in the socialization of the younger generation, formation of professional background not only for the members of the dynasty, but also for others. At the same time, academic dynasties become the center of successfully operating scientific collectives. Dynasties are also carriers of professional standards, ensuring the sustainable development of the scientific environment. However, the dynasty can be not only a scientific activity succession mechanism, but also a monopoly that creates filters, promotes closeness of the scientific community, that shows its destructive potential.
\end{abstract}

Keywords: academic dynasty, professionalism, monopoly, resources, symbolic capital

ДУБРОВИНА Ольга Юрьевна - кандидат политических наук, доцент Сибирского института международных отношений и регионоведения (630075, Россия, г. Новосибирск, ул. Народная, 14; olgadubrovina@mail.ru)

\section{ПОЛИТИКО-ПРАВОВОЕ РЕГУЛИРОВАНИЕ МЕЖДУНАРОДНОГО СОТРУДНИЧЕСТВА РЕГИОНОВ: АКТУАЛЬНОСТЬ И ОСОБЫЕ ПРИНЦИПЫ}

Аннотация. Статья посвящена политико-правовому регулированию международного сотрудничества регионов государств (МСР). Основное внимание уделено актуальности и особым принципам политикоправового регулирования МСР: принципу регионализации, федерализации, автономии, самоуправления, децентрализации, субсидиарности, принципу рационального распределения функций и разграничения полномочий в сфере международных отношений и связей между государством и его регионами, принципу координации международных связей регионов, принципу гармонизации правового пространства международной деятельности государства и его регионов, принципу либерализации экономики. Анализируя все эти принципы, автор рассматривает их во взаимосвязи и взаимозависимости. Ключевые слова: глобализация, регионализация, государство, регионы государств, международные связи регионов, особые принципы международных связей регионов государств, автономия, самоуправление, децентрализация, разграничение полномочий, гармонизация правового пространства, либерализация экономики, принципы

$\mathrm{P}$ егионы государств во второй половине XX в. стали активно выходить на международную арену, а в начале XXI в. они превратились в существен- 